\title{
MODEL OPTIMALISASI FUNGSI PASAR TRADISIONAL DI KOTA BANDA ACEH (Studi Kasus Pasar Newtown Lamdom)
}

\author{
I Sa'dan'), N Fadhli' ${ }^{2)}$, Ashfa ${ }^{3)}$ \\ ${ }^{1,2,3)}$ Magister Teknik Sipil, Universitas Syiah Kuala, Banda Aceh, Indonesia \\ Email:ibnusakdan2222@ gmail.com ${ }^{1)}$ noer6637@unsyiah.ac.id ${ }^{2}$ \\ ashfa.achmad@unsyiah.ac.id ${ }^{3)}$
}

DOI: http://dx.doi.org/10.29103/tj.v11i2.521

(Received: April 2021 / Revised: August 2021 / Accepted: September 2021)

\begin{abstract}
Abstrak
Pasar tradisional adalah salah satu aspek yang dapat menunjang pertumbuhan ekonomi di Kota Banda Aceh. Pasar Tradisional Newtown Lamdom (PTNL) merupakan salah satu pasar tradisional di Kota Banda Aceh yang belum berfungsi sebagaimana mestinya, tidak ada satupun pedagang yang berjualan di sana. Penelitian ini bertujuan untuk mengetahui faktor-faktor apa saja yang memiliki pengaruh terhadap tidak optimalnya fungsi PTNL dan merumuskan strategi dalam meningkatkan pengelolaan PTNL. Strategi dalam mengoptimalkan fungsi pasar tradisional sudah diidentifikasi dengan menyebarkan kuesioner melalui observasi lapangan dan melalui google form, data kuesioner diolah menggunakan metode analisis regresi ordinal, kemudian akan diperoleh hasil penyebab tidak optimalnya fungsi pasar tradisional Newtown Lamdom selanjutnya, faktor-faktor tersebut dianalisis dengan menggunakan metode Focus Group Discussion $(F G D)$. hasil dari serangkaian analisis yang dilakukan menunjukkan bahwa lokasi PTNL memiliki pengaruh 82,1\%, sarana PTNL memiliki pengaruh sebesar 74,7\% dan prasarana PTNL memiliki pengaruh sebesar 22,7\% terhadap factor yang mempengaruhi tidak optimalnya fungsi PTNL, untuk dapat mengoptimalkan fungsi PTNL perlu menyiapkan lokasi dan sarana sesuai dengan kebutuhan pasar seperti ketersedian lahan parkir, tersedianya transportasi umum menuju pasar, air bersih, listrik dan ketersediaan bahan baku, selain itu juga perlu ditinjau aspek kebijakan pemerintah seperti melakukan sosialisasi kepada pedagang dan pembeli untuk dapat mengoptimalkan fungsi PTNL.
\end{abstract}

Kata Kunci: Strategi, optimalisasi pasar, pasar tradisional, fungsi pasar

\begin{abstract}
Traditional market is one of the supporting aspects for economic growth in Banda Aceh. Newtown Lamdom Market (PTNL) is one of traditional markets in Banda Aceh that has not been functioning properly from year to year as there is no single trader who sells there. This study aims to determine the factors causing the function of the traditional market is not optimal and to formulate the strategy in order to improve the management of Newtown Lamdom Traditional Market. The author identified the strategy in optimizing the function of traditional market by conducting field observation. The results of observation are then analyzed by using the Ordinal Regression Method to determine the factors causing the function of the traditional market are not optimal. Afterwards, those factors are analyzed through Focus Group Discussion (FGD) with the determined informants. The results of series of analyses conducted show that the City Government of Banda Aceh is required to rehabilitate the Newtown Lamdom market buildings, equip the market facilities and infrastructure, provide raw material
\end{abstract}


needs, and conduct socialization to traders and buyers in order to optimize the function of Newtown Lamdom Market.

Keywords: Strategy, Market Optimization, Traditional Market, market function

\section{Latar Belakang}

Pasar tradisional merupakan salah satu tempat yang terbuka di mana terjadi proses transaksi jual beli yang dapat memungkinkan terjadinya proses tawar menawar, di pasar tradisional pengunjung tidak selamanya menjadi pembeli, namun pengunjung bisa juga menjadi penjual, bahkan setiap orang bisa menjual dagangannya di pasar tradisional. Pasar tradisional merupakan sektor perekonomian yang sangat penting bagi mayoritas penduduk di Indonesia. Masyarakat miskin yang bergantung kehidupannya pada pasar tradisional tidak sedikit, menjadi pedagang di pasar tradisional merupakan alternatif pekerjaan di tengah banyaknya pengangguran di Indonesia (Surya, 2015).

Pasar Newtown Lamdom merupakan salah satu pasar tradisional yang terletak di Desa Lamdom, Kecamatan Lueng Bata, Kota Banda Aceh. Pasar ini dibangun pada tahun 2008. Dinas Koperasi UKM dan Perdagangan Kota Banda Aceh sebagai instansi pengelola pernah memfungsikan pasar Newtown Lamdom ini tetapi hanya beroperasi beberapa bulan saja. (Darma, Aulia and Safwan, 2018) menganalisis pengelolaan kawasan pasar ulee kareng Kota Banda Aceh. Hasil dari penelitan ini menunjukkan bahwa faktor yang mempengaruhi tidak berfungsinya pasar tradisional, diantaranya lokasi pasar yang tidak strategis, kondisi pasar yang memprihatinkan serta sarana dan prasarana yang belum memadai.

(Dewi, 2018) menganalisis permasalahan yang sering terjadi pada pasar tradisional sekarang ini adalah pasar tersebut mulai ditinggalkan oleh masyarakat yang disebabkan karena banyak hadir pasar modern di sekitar masyarakat seperti minimarket, hypermarket, dan lain lain. (Syahputra, Afifuddin and Yusuf, 2018) menganalisis faktor-faktor yang mempengaruhi tidak berfungsinya pasar tradisional lamgapang. Dalam penelitian sebelumnya yang dilakukan oleh (Syahputra, Afifuddin and Yusuf, 2018) dan (Darma, Aulia and Safwan, 2018) hanya menganalisis faktor-faktor tidak berfungsinya pasar tradisional dan tidak menjelaskan solusi dalam mengoptimalkan fungsi pasar tradisional sehingga belum diketahui bagaimana cara mengoptimalkan fungsi pasar tradisional.

Sehubungan dengan permasalahan tersebut, perlu dilakukan kajian model optimalisasi fungsi pasar tradisional di Kota Banda Aceh (studi kasus Pasar Newtown Lamdom), selanjutnya model tersebut dapat memberikan masukan kepada pemerintah dalam mengoptimalkan fungsi pasar tradisional. Tujuan dari penelitian ini adalah untuk mengetahui faktor-faktor apa saja yang dapat mempengaruhi tidak optimalnya fungsi infrastruktur PTNL dan untuk mengetahui strategi mengoptimalkan fungsi infrastruktur PTNL.

\section{Metode Penelitian}

\subsection{Gambaran Umum Lokasi Penelitian}

Penelitian ini dilakukan pada PTNL yang berlokasi di Desa Lamdom, Kecamatan Lueng Bata, Kota Banda Aceh, Provinsi Aceh. Secara administrasi wilayah Kota Banda Aceh meliputi 9 Kecamatan dan 90 desa dengan luas wilayah keseluruhan lebih kurang sekitar 61,36 KM2. 


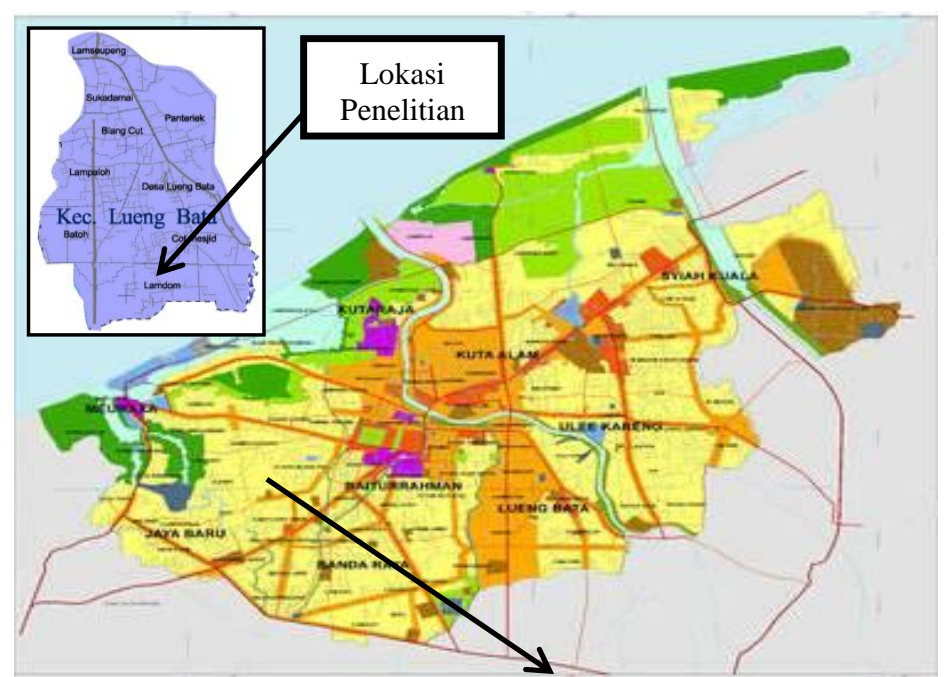

Gambar 1 Lokasi Penelitian

\subsection{Teknik Pengumpulan Data}

Teknik pengumpulan data dapat dilakukan dengan interview, kuesioner, observasi, dan gabungan ketiganya, pengumpulan data dilakukan untuk mendapatkan sejumlah informasi dari berbagai sumber yang diperlukan dalam menyelesaikan penelitian (Pengantar and Semiawan, 2020). Adapun teknik pengumpulan data yang diperlukan, yaitu Data primer ialah data yang diperoleh atau dikumpulkan langsung di lapangan. Data primer yang dibutuhkan dalam penelitian ini adalah sebagai berikut:

a. Data Kuesioner diperoleh dengan menyebarkan kuesioner kepada masyarakat di desa Lamdom sebanyak 100 Responden.

b. Data FGD diperoleh dengan melakukan FGD terhadap 8 informan yang terdiri dari unsur pemerintah dan unsur masyarakat desa lamdom

\subsubsection{Penentuan Sampel}

Untuk mendapatkan data-data langkah pertama yang dilakukan menentukan populasi penelitian supaya penelitian mendapat kejelasan mengenai subjek penelitian. Teknik sampling yang digunakan adalah sampling incidental yaitu teknik pengambilan sampel yang dilakukan berdasarkan secara kebetulan, yaitu siapa saja yang secara kebetulan bertemu dapat digunakan sebagai sampel (Sugiyono,2011).

Tabel 1 Jumlah penduduk kecamatan Lueng Bata

\begin{tabular}{clccc}
\hline \multirow{2}{*}{ No } & \multicolumn{1}{c}{ Desa } & $\begin{array}{c}\text { Luas } \\
\text { Wilayah }\end{array}$ & $\begin{array}{c}\text { Jumlah Rumah } \\
\text { Tangga }\end{array}$ & $\begin{array}{c}\text { Jumlah } \\
\text { Penduduk }\end{array}$ \\
\hline 1 & Batoh & $135,5 \mathrm{Ha}$ & $1112 \mathrm{RT}$ & 5878 jiwa \\
\hline 2 & Blang Cut & $52,2 \mathrm{Ha}$ & $482 \mathrm{RT}$ & 1793 jiwa \\
\hline 3 & Cot Mesjid & $34,6 \mathrm{Ha}$ & $811 \mathrm{RT}$ & 4104 jiwa \\
\hline $\mathbf{4}$ & Lamdom & $\mathbf{7 3 , 8 ~ H a}$ & $\mathbf{5 3 9} \mathrm{RT}$ & $\mathbf{2 1 5 0}$ jiwa \\
\hline 5 & Lampaloh & $13,3 \mathrm{Ha}$ & $164 \mathrm{RT}$ & 649 jiwa \\
\hline 6 & Lamseupeung & $76,8 \mathrm{Ha}$ & $512 \mathrm{RT}$ & 2963 jiwa \\
\hline 7 & Lueng Bata & $66,4 \mathrm{Ha}$ & $999 \mathrm{RT}$ & 3372 jiwa \\
\hline 8 & Panteriek & $51,3 \mathrm{Ha}$ & $1161 \mathrm{RT}$ & 4462 jiwa \\
\hline 9 & Sukadamai & $30,2 \mathrm{Ha}$ & $437 \mathrm{RT}$ & 1609 jiwa \\
\hline
\end{tabular}

Sumber: ('SIMKAP.Banda Aceh, 2021) 
Adapun perhitungan sampel pada penelitian ini menggunakan rumus Slovin, sebagai berikut:

di mana:

$$
n=\frac{N}{1+N x e^{2}}
$$

$$
\begin{aligned}
& \mathrm{n}: \text { Jumlah Sampel } \\
& \mathrm{N}: \text { Jumlah populasi } \\
& \mathrm{e}: \text { Nilai Margin of Error } \\
& \mathrm{n}=\frac{2150}{1+2150 \times 0,1^{2}} \\
& \mathrm{n}=95,55=100 \text { Sampel }
\end{aligned}
$$

Tingkat kepercayaan adalah $90 \%$ dan nilai tingkat kesalahannya yaitu $10 \%$, karakteristik responden adalah masyarakat berdomisili di desa Lamdom Kecamatan Lueng Bata, mengetahui tentang keberadaan PTNL dan pernah datang ke PTNL

\subsubsection{Kuesioner}

Kuesioner yang digunakan merupakan jenis kuesioner tertutup, responden hanya dapat memilih dari jawaban yang telah disediakan. Dalam hal ini kuesioner terbagi kepada 2 (dua) bagian yaitu kuesioner bagian A menanyakan tentang karakteristik pembeli/masyarakat di sekitar dan pedagang; kuesioner bagian B, menanyakan tentang faktor-faktor yang mempengaruhi tidak optimalnya fungsi PTNL. Adapun pengukuran jawabannya dengan menggunakan skala semantic diferenstial:

\begin{tabular}{|l|l|l|l|l|l|l|l|l|}
\hline Sangat Setuju & 7 & 6 & 5 & 4 & 3 & 2 & 1 & Sangat Tidak Setuju \\
\hline
\end{tabular}

Setelah merancang kuesioner melakukan penyebaran kuesioner. Penyebaran kuesioner ini memiliki tujuan untuk mendapatkan data persepsi responden mengenai faktor-faktor apa saja yang dapat mempengaruhi tidak optimalnya fungsi PTNL. Langkah yang dilakukan dalam penyebaran kuesioner melakukan observasi lapangan dan penyebaran melalui google form.

\subsection{Analisis Data Ordinal}

Regresi ordinal merupakan salah satu dari berbagai jenis analisis yang khusus digunakan jika variabel dependen merupakan data berskala kategori bertingkat (Meiza et al., 2020). Istilah katagori bertingkat juga biasanya disebut dengan istilah ordinal atau rangking. Tujuan Regresi ordinal adalah untuk membentuk komponen yang dapat menangkap informasi dari variabel bebas untuk memprediksi variabel terikat. Adapun variabel dalam penelitian ini sebagai berikut:

1. Variabel Bebas $(\mathrm{X})$

Variabel bebas merupakan variabel yang dapat mempengaruhi atau yang menjadi sebab perubahan atau timbulnya variabel dependen/terikat. (Gunawan, 2015) Penyebutan variabel bebas sering juga disebut sebagai stimulus/ eksogen/independent. Variabel bebas yang digunakan dalam penelitian ini dapat dilihat pada Tabel 2 . 
Tabel 2 Variabel bebas

\begin{tabular}{|c|c|c|}
\hline No & Variabel & Indikator \\
\hline \multirow[t]{4}{*}{1} & \multirow[t]{4}{*}{ Lokasi Pasar (x1) } & Dekat dengan Jalan Utama \\
\hline & & Tersedianya parkir \\
\hline & & Tersedianya transportasi umum \\
\hline & & Dekat dengan bahan baku \\
\hline \multicolumn{3}{|c|}{ Sumber: (Yopiannor, 2017) } \\
\hline \multirow[t]{7}{*}{2} & \multirow[t]{7}{*}{ Sarana Pasar (x2) } & Tersedianya jaringan air bersih \\
\hline & & Tersedianya jaringan listrik \\
\hline & & Tersedianya akses langsung dari parkir menuju kios pasar \\
\hline & & Tersedianya ATM centre \\
\hline & & Akses keluar masuk yang banyak \\
\hline & & Tersedianya Alat pemadam Api Ringan \\
\hline & & Sirkulasi udara dan pencahayaan yang baik \\
\hline \multicolumn{3}{|c|}{ Sumber: (Hidayat 2018) } \\
\hline \multirow[t]{10}{*}{3} & \multirow[t]{10}{*}{ Prasarana Pasar (x3) } & Tersedianya bangunan kios \\
\hline & & Tersedianya bangunan los \\
\hline & & Tersedianya area penghijauan \\
\hline & & Tersedianya Toilet/WC \\
\hline & & Tersedianya Mushalla \\
\hline & & Tersedianya pos pengamanan \\
\hline & & Tersedianya layanan kesehatan \\
\hline & & Tersedianya fasilitas bongkar muat \\
\hline & & Tersedianya jalan keliling pasar \\
\hline & & Tersedianya Tempat Penimbunan Sampah (TPS) \\
\hline
\end{tabular}

Sumber: (Surya, 2015)

2. Variabel Terikat (Y)

Pengertian variabel terikat merupakat variabel yang menjadi akibat karena adanya variabel bebas. Variabel terikat juga biasa disebut sebagai variabel dependen atau output/kriteria/konsekuen/endogen.

Tabel 3 Varibel terikat

\begin{tabular}{|c|c|}
\hline Variabel & Indikator \\
\hline \multirow{5}{*}{$\begin{array}{c}\text { Fungsi Pasar } \\
\text { Tradisional (y) }\end{array}$} & Pasar sebagai tempat pengumpulan hasil pertanian \\
\hline & Pasar sebagai tempat distribusi barang industri \\
\hline & Pasar sebagai tempat menukar barang kebutuhan \\
\hline & Pasar sebagai tempat jual beli barang dan jasa \\
\hline & Pasar sebagai tempat informasi perdagangan \\
\hline
\end{tabular}

\subsection{Analisis FGD}

Focus Group Discussion (FGD) sebuah Teknik pengumpulan data yang dilakukan dalam penelitian kualitatif dengan tujuan menemukan makna sebuah tema menurut pemahaman sebuah kelompok (Gunawan, 2015). Teknik sampling yang digunakan merupakan purposive sampling, menurut (Gunawan, 2015) adalah teknik pengambilan sampel dengan pertimbangan tertentu. Alasan menggunakan dikarenakan tidak semua sampel memiliki kriteria yang sesuai dengan fenomena yang diteliti, oleh karena itu dipilih Teknik purposive sampling yang dapat menetapkan pertimbangan atau kriteria tertentu yang harus dipenuhi oleh sampel yang digunakan. 
Sampel (peserta FGD) terdiri dari beberapa unsur, yaitu unsur masyarakat 5 orang, unsur pemerintah Kota Banda Aceh/Bappeda (owner) 1 orang dan unsur Disperindag (pengelola) 2 orang yang dipilih berdasarkan kemampuan dan kompetensi serta kometensi penguasaan focus masalah FGD. Kriteria yang dijadikan sebagai sampel penelitian sebagai berikut:

1. Unsur Masyarakat (User)

a. Berdomisili di desa Lamdom Kecamatan Lueng Bata

b. Sudah berkeluarga

2. Unsur Pemerintah/ Bappeda Kota Banda Aceh (Owner)

a. Pegawai Pemerintah/Bappeda Kota Banda Aceh

b. Pejabat/staf Bidang/Bagian Ekonomi

3. Unsur Disperindag (Pengelola)

a. Pegawai Disperidag

b. Pejabat/staf Bidang/Bagian Perdagangan

Model Analisa data yang digunakan pada penelitian ini adalah analisis deskriptif dimaksudkan sebagai prosedur pemecahan masalah yang diselidiki dengan menggambarkan/melukiskan keadaan subjek, objek penelitian (seseorang, Lembaga, masyarakat dan lain-lain) saat sekarang berdasarkan fakta yang tampak atau sebagaimana adanya. Penelitian dilakukan dengan beberapa tahapan:

1. Peneliti melakukan FGD deng 5 orang dari unsur masyarkat (user), 2 orang dari unsur Disperindag (pengelola) dan 1 orang dari unsur Bappeda Kota Banda Aceh (Owner) sebagai seubjek penelitian;

2. Peneliti membuat hasil FGD ke dalam tulisan dan selanjutnya menganalisis hasil tersebut;

3. Peneliti membuat naratif dari hasil analisis dan FGD;

4. Setelah data dianalisis, tahap yang terakhir adalah menyajikan hasil penelitian.

\section{Hasil dan Pembahasan}

\subsection{Statistik Deskriptif}

Data primer berupa hasil penyebaran kuesioner kepada 100 responden yaitu masyarakat desa lamdom, dan hasil diskusi dengan informan FGD. Informan terdiri dari unsur Pemerintah Kota Banda Aceh dan unsur masyarakat di desa Lamdom, secara lebih rinci dapat dilihat pada Tabel 4.

Tabel 4 Karakteristik responden

\begin{tabular}{clcc}
\hline No & Keterangan & Jumlah & Persentase $\%$ \\
\hline 1 & Jenis Kelamin & & \\
\hline \multicolumn{2}{l}{ Laki - Laki } & 28 & 28,00 \\
\hline Perempuan & 72 & 72,00 \\
\hline Total & 100 & 100 \\
\hline 2 & Usia & \\
\hline & $<25$ Tahun & 12 & 12,00 \\
\hline & 25 - 35 Tahun & 63 & 63,00 \\
\hline & $>35$ Tahun & 25 & 25,00 \\
\hline & Total & 100 & 100 \\
\hline
\end{tabular}

Dari Tabel 4 menunjukkan karakteristik responden meliputi jenis kelamin dan usia. Jenis kelamin responden mayoritas perempuan yaitu 28 orang $(76 \%)$ dan 
sisanya laki-laki sebesar 12 orang (24\%). Usia responden mayoritas berusia antara 25-35 tahun sebanyak 24 orang (48\%), di bawah itu berusia diatas 35 tahun 18 orang (36\%) dan yang berusia di bawah 25 tahun sebanyak 8 orang $(16 \%)$.

\subsection{Pembahasan Penelitian}

\subsubsection{Hasil Analisis Regresi PLS}

Berikut ini adalah hasil pendugaan model regresi logistik ordinal faktor yang mempengaruhi tidak optimalnya fugsi infrastruktur PTNL menggunakan software SPSS 25, hasil model regresi dapat dilihat pada Tabel 5.

Tabel 5 Model regresi

\begin{tabular}{|c|c|c|c|c|c|c|c|c|}
\hline & \multirow{2}{*}{ Estimate } & \multirow{2}{*}{$\begin{array}{l}\text { Std. } \\
\text { Error }\end{array}$} & \multirow{2}{*}{ Wald } & \multirow{2}{*}{ df } & \multirow{2}{*}{ Sig. } & \multicolumn{2}{|c|}{$95 \%$ confidaence Interval } \\
\hline & & & & & & & Lower Bound & Upper Bound \\
\hline \multirow[t]{3}{*}{ Threshold } & {$[\mathrm{Y}=5]$} & 16.223 & 3.575 & 20.591 & 1 & .000 & 9.216 & 23.230 \\
\hline & {$[\mathrm{Y}=6]$} & 23.327 & 4.214 & 30.637 & 1 & .000 & 15.067 & 31.588 \\
\hline & {$[\mathrm{Y}=7]$} & 31.493 & 5.370 & 34.393 & 1 & .000 & 20.968 & 42.019 \\
\hline \multirow[t]{3}{*}{ Location } & Lokasi & .538 & .115 & 21.937 & 1 & .000 & .313 & .763 \\
\hline & Sarana & .641 & .196 & 10.709 & 1 & .001 & .257 & 1.025 \\
\hline & Prasarana & .052 & .047 & 1.216 & 1 & .270 & -.040 & .144 \\
\hline
\end{tabular}

Dari output pada Tabel 5 variabel konstanta $(\Theta)$ bisa dilihat pada kolom estimate dan pada baris threshold dengan nilai masing-masing sebesar 16,223, 23,327 dan 31,493 sedangkan nila $\beta$ merupakan nilai variabel predictor, jika dilihat dari output di atas variable predictor bisa dilihat pada kolom estimate dan pada baris Location dengan nilai masing-masing sebesar 0,538, 0,641 dan 0,052.

\section{A. Uji Wald}

Hasil pengujian parameter Wald pada Tabel 6 menjelaskan bahwa variabel lokasi pasar dan variabel sarana pasar adalah variable yang mempunyai pengaruh signifikan terhadap tidak optimalnya fungsi infrastruktur PTNL dikarenakan beberapa variabel tersebut mempunyai nilai signifikan $<\alpha(0,05)$ sedangkan untuk variabel prasarana pasar tidak memiliki pengaruh yang signifikan terhadap faktor tidak optimalnya fungsi infrastruktur PTNL ini menunjukkan variabel prasarana PTNL yang sudah ada, sudah cukup bagus menurut penilaian masyarakat. Hasil pengujian wald bisa dilihat dari pada Table 6.

Tabel 6 Uji wald

\begin{tabular}{|c|c|c|c|c|c|c|c|c|}
\hline & \multirow[b]{2}{*}{ Estimate } & \multirow[b]{2}{*}{ Std. Error } & \multirow[b]{2}{*}{ Wald } & \multirow[b]{2}{*}{$\mathrm{df}$} & \multirow[b]{2}{*}{ Sig. } & \multicolumn{2}{|c|}{$95 \%$ Confidence Interval } \\
\hline & & & & & & & Lower Bound & Upper Bound \\
\hline \multirow[t]{3}{*}{ Threshold } & {$[\mathrm{Y}=5]$} & 16.223 & 3.575 & 20.591 & 1 & .000 & 9.216 & 23.230 \\
\hline & {$[\mathrm{Y}=6]$} & 23.327 & 4.214 & 30.637 & 1 & .000 & 15.067 & 31.588 \\
\hline & {$[\mathrm{Y}=7]$} & 31.493 & 5.370 & 34.393 & 1 & .000 & 20.968 & 42.019 \\
\hline \multirow[t]{3}{*}{ Location } & Lokasi & .538 & .115 & 21.937 & 1 & .000 & .313 & .763 \\
\hline & Sarana & .641 & .196 & 10.709 & 1 & .001 & .257 & 1.025 \\
\hline & Prasarana & .052 & .047 & 1.216 & 1 & .270 & -.040 & .144 \\
\hline
\end{tabular}

Link Function: Link function: Logit. 


\section{B. Uji Determinasi Model}

Besarnya nilai koefisien determinasi pada model regresi logistic ditunjukkan oleh nilai Mc Fadden, Cox dan Snell, Nagelkerke R Square. determinasi dapat dilihat pada Tabel 7 .

Tabel 7 Koefisien determinasi

\section{Pseudo R-Square}

\begin{tabular}{lc} 
Cox and Snell & .770 \\
\hline Nagelkerke & .869 \\
\hline McFadden & .676 \\
\hline
\end{tabular}

Link function: Logit

Tabel 7 menunjukkan nilai koefisien determinasi Mc Fadden sebesar 0,676 sedangkan koefisien determinasi Cox dan Snell sebesar 0,770 dan koefisien determinasi Nagelker sebesar 0,869 atau sebesar 86,9\%. Koefisien Nagelkerke sebesar $86,9 \%$ berarti variabel independent aspek lokasi pasar, aspek sarana pasar dan aspek prasarana pasar mempengaruhi fungsi infrastruktur PTNL sebesar $86,9 \%$ sedangkan $13,1 \%$ dipengaruhi oleh faktor lain yang tidak termasuk dalam pengujian model.

\subsubsection{Pembahasan Hasil Penelitian}

Berdasarkan hasil analisis dari 100 responden di Desa Lamdom sebanyak 83 responden mengetahui keberadaan PTNL sedangkan 17 responden tidak mengetahui keberadaan PTNL. Berdasarkan pernah datang ke lokasi PTNL diketahui sebanyak 78 responden pernah datang ke lokasi PTNL, sedangkan 22 responden tidak pernah datang ke lokasi PTNL.

Dari hasil penelitian maka dapat disimpulkan bahwa faktor-faktor yang mempengaruhi tidak optimalnya fungsi PTNL adalah Lokasi pasar dan Sarana Pasar, sedangkan Prasarana pasar di PTNL bisa diartikan sudah lumanyan lengkap walaupun masih ada sedikit kerusakan karena faktor jarang digunakan sehingga masih diperlukan perbaikan pada prasarana pasar.

\subsubsection{Hasil Analisis Focus Group Discussion}

Focus Group Discussion (FGD) dalam penelitian ini dilakukan pada tanggal 30 maret 2021 yang terdiri dari fasilitator, notulen dan peserta FGD, adapun peserta yang mengikuti kegiatan FGD dapat dilihat pada Tabel 8.

Tabel 8 Peserta Focus Group Discussion

\begin{tabular}{clll}
\hline No & \multicolumn{1}{c}{ Informan } & \multicolumn{1}{c}{ Unsur } & \multicolumn{1}{c}{ Pekerjaan } \\
\hline 1 & Rizki Munandar & Pemerintah Kota Banda Aceh & Bidang Ekonomi Bappeda \\
\hline 2 & Yuli Ramadhani & Pemerintah Kota Banda Aceh & Bidang Pemasaran Disperindag \\
\hline 3 & Ervin & Pemerintah Kota Banda Aceh & Bidang Pemasaran Disperindag \\
\hline 4 & Zulhamdi & Masyarakat & Dosen \\
\hline 5 & Aira & Masyarakat & Wiraswasta \\
\hline 6 & Cut Azlina & Masyarakat & PNS \\
\hline 7 & Yopi & Masyarakat & Pedagang \\
\hline 8 & Suci & Masyarakat & IRT \\
\hline
\end{tabular}


Dalam kegiatan diskusi tersebut selain informan juga hadir notulen dan diskusi dipandu oleh fasilitator. Setelah dilakukan diskusi dilakukan analisis untuk mendapatkan strategi dalam mengoptimalkan fungsi PTNL. Dalam diskusi muncul beberapa informasi terkait PTNL bahwa PTNL pernah difungsikan oleh disperindag namun tidak bertahan lama, karena sedikitnya pengunjung yang hadir, sedangkan menurut informasi dari masyarakat, menyebutkan bahwa PTNL tidak lengkap sehingga masyarakat lebih memilih berbelanja di pasar Lambaro dan Peunayong padahal kalau di pasar Lamdom lengkap bermanfaat bagi masyarakat karena tidak perlu jauh pergi ke pasar. Strategi yang ditawarkan oleh unsur Disperindag/pengelola pasar dijadikan pasar khusus seperti pasar sayur atau pasar ikan atau pasar burung atau tempat kuliner supaya pemenuhan kebutuhan lebih mudah dipenuhi sesuai kebutuhan pasar karena terfokus terhadap bahan baku tertentu dibandingkan dengan menjadikan pasar tersebut bersifat umum, semua akan mengalami kesulitan dalam memenuhi kebutuhan, selain itu juga harus melakukan sosialisasi kepada pedagang dan pembeli untuk mengoptimalkan fungsi pasar karena tanpa sosialisasi yang baik tidak akan terjadi transaksi di PTNL. Dari hasil FGD dirangkum dan dianalisis untuk menentukan strategi dalam mengoptimalkan fungsi PTNL yaitu:

1. Owner (Menjadikan lokasi pasar newtown lamdom sebagai tempat wisata kuliner, Pemerintah Kota Banda Aceh perlu melakukan rehabilitasi gedung pasar Newtown Lamdom)

2. Pengelola (Pasar Newtown Lamdom dijadikan pasar kusus, seperti pasar ikan, pasar sayur, pasar burung, atau wisata kuliner yang bersifat khusus; Pemerintah melakukan sosialisasi kepada pedagang dan pembeli)

3. User (Pemerintah Kota Banda Aceh perlu melengkapi sarana dan prasarana pasar dengan lengkap; Pemerintah perlu menyediakan lokasi parkir yang memadai; Menyediakan transportasi umum yang menuju PTNL; Menyediakan kebutuhan bahan baku pada pasar Newtown Lamdom)

Dari hasil Focus Group Discussion didapat variabel baru dalam mengoptimalkan fungsi infrastruktur PTNL yaitu Aspek kebijakan pemerintah, selain dari variabel yang sudah di teliti yaitu variabel lokasi pasar, sarana pasar dan prasarana pasar.

\section{Kesimpulan dan Saran}

\subsection{Kesimpulan}

Kesimpulan dari keseluruhan proses penelitian ini adalah Lokasi PTNL memiliki pengaruh $82,1 \%$, sarana PTNL memiliki pengaruh $74,7 \%$ dan prasarana PTNL memiliki pengaruh $22,7 \%$ terhadap faktor yang mempengaruhi tidak optimalnya fungsi PTNL; Untuk dapat mengoptimalkan fungsi PTNL perlu menyiapkan lokasi dan sarana pasar sesuai dengan kebutuhan pasar seperti ketersediaan lahan parkir, tersedianya transportasi umum menuju pasar, air bersih, listrik dan ketersedian bahan baku selain itu juga perlu ditinjau aspek kebijakan pemerintah sepeti melakukan sosialisasi kepada pedagang dan pembeli untuk dapat mengoptimalkan fungsi PTNL 


\subsection{Saran}

Saran yang dapat dikemukakan untuk mengoptimalkan fungsi pasar tradisional perlu memperhatikan faktor yang paling berpengaruh pada PTNL dalam mengoptimalkan fungsi PTNL, perlu menyiapkan lokasi dan sarana pasar sesuai dengan kebutuhan pasar seperti ketersediaan lahan parkir, tersedianya transportasi umum menuju pasar, air bersih, listrik dan ketersedian bahan baku selain itu juga perlu di tinjau aspek kebijakan pemerintah sepeti melakukan sosialisasi kepada pedagang dan pembeli untuk dapat mengoptimalkan fungsi PTNL.

\section{Daftar Kepustakaan}

Darma, T. S., Aulia, T. B. and Safwan, S, 2018. Optimalisasi Pengelolaan Kawasan Pasar ulee Kareng Kota Banda Aceh. JARSP, 1(2), pp. 80-89. doi: 10.24815/jarsp.v1i2.10946.

Dewi R, S, 2018. Pengaruh Faktor Modal Psikologis, Terhadap Perkembangan Usaha Pedagang Di Pasar Tradisional (Studi kasus pada Pedagang Sembako dan Snack di Pasar Peterongan). J. Adm. Bisnis, vol. 2, no. 1, pp. 29-40, doi: 10.14710/jab.v2i1.5352.

Gunawan, I, 2018. Metode Penelitian Kualitatif. p. 27.

Meiza, A. et al, 2020. Analisis Regresi Ordinal untuk melihat Pengaruh Media Pembelajaran Daring terhadap Antusiasme Mahasiswa Era Pandemi Covid. p. 8.

Pengantar, K. and Semiawan, D. C. R, 2020. Jenis, Karakteristik, dan Keunggulannya. p. 171.

Sugiyono, 2011. Metode Penelitian Kuantitatif Kualitatif dan R\&D. Alfabeta, Bandung

Safitri, 2016. Strategi Pengelolaan Pasar Tradisional Mauk Di Kecamatan Mauk Kabupaten Tanggerang.

http://simkap.bandaacehkota.

Surya, B, 2015. Optimization of Function and Role of Traditional Markets in Urban Development Systems of Ketapang City (A Case Study: Range Sentap Market, Delta Pawan Subdistrict, Ketapang City). Asian Journal of Applied Sciences, 03(06), p. 16.

Syahputra, M. Afifuddin, and S. Yusuf, 2018. Faktor-Faktor Yang Mempengaruhi Tidak Berfungsinya Pasar Tradisional (Studi Kasus: Pasar Lamgapang Kecamatan Ulee Kareng Kota Banda Aceh ). J. Arsip Rekayasa Sipil dan Perenc., vol. 1, no. 1, pp. 112-121, 2018, doi: 10.24815/jarsp.v1i1.10361.

Yopiannor, F. Z, 2017. Strategi Meningkatkan Daya Saing Pasar Tradisional (Kasus Revitalisasi Pasar Tradisional di Kota Banjarmasin). Restorica: Jurnal Ilmiah Ilmu Administrasi Negara dan Ilmu Komunikasi, 3(1), pp. 85-90. doi: 10.33084/restorica.v3i1.630.

\section{Copyright (c) I Sa'dan, N Fadhli, Ashfa}

